\title{
THE IMPORTANCE OF STONE RETRIEVAL IN THE MODERN MANAGEMENT OF UROLITHIASIS
}

Ahman Khela ${ }^{1}$, Manoj Ravindranaadan ${ }^{1}$, Adam Jones ${ }^{1}$, Adnan Asghar, ${ }^{1}$ Wasim Mahmalji ${ }^{1}$

${ }^{1}$ Hereford County Hospital, Hereford

Corresponding Author: aman.khela@nhs.net

Submitted: November 29, 2019. Accepted: December 13, 2019. Published: March 2, 2020.

\begin{abstract}
\section{Background and Objectives}

World urolithiasis is increasing with a 70\% increase in hospital admissions between 2000 and 2015. Stone analysis can allow for the identification of metabolic conditions and stone retrieval may decrease the need for follow-up imaging, reducing costs and patient radiation.

This study aimed to see if introducing the $\mathrm{UroPro}^{\odot}$ Stone catcher into our practise would increase stone retrieval thus increasing stone analysis rates and reducing the need for follow-up imaging.
\end{abstract}

\section{Methods}

Between November 2018 and July 2019 patients receiving ESWL or being conservatively managed for a ureteric stone were discharged with a Paramount Medical solutions UroPro ${ }^{\odot}$ Stone Catcher. Both groups of patients were asked to complete a patient survey regarding the product.

\section{Results}

There were 27 patients recruited. 14 from SWL and 13 from acute admissions. 22 responses were received in total: 10 from acute admissions and 12 from ESWL. 5 patients were uncontactable. $30 \%(n=3)$ of the acute patients passed and caught a stone negating the need for further imaging. $30 \%(\mathrm{n}=3)$ did not pass their stone and required either emergency or elective intervention. 1 patient passed his stone into the toilet whilst another had the stone in their bladder when they were taken to theatre. $20 \%(\mathrm{n}=2)$ patients but did not catch their stone requiring follow-up imaging which revealed the stone had passed. In the ESWL group $16 \%(n=2)$ caught a fragment, the rest found they only passed dust. Stone analysis was performed in all 5 patients who returned a fragment.

A total of $73 \%(n=16)$ of patients reported over $75 \%$ compliance with the stone catcher. $59 \%(n=13)$ reported that the stone catcher was easy to use whilst $27 \%(n=6)$ found it hard. When given a choice of sieving methods. Only 6 patients (27\%) would opt to use the stone catcher with over half, $64 \%(n=14)$, preferring more traditional methods of sieving urine over the stone catcher.

\section{Conclusion}

$\mathrm{The} \mathrm{UroPro}^{\odot}$ stone catcher did increase the number of stones caught and sent for analysis. However, many patients preferred the older 'sieving' methods. Stone catchers retail at $£ 5.50$, therefore 'sieving' remains more cost-effective. Stone retrieval in any form remains advantageous as confirming stone passage saves 
the patient 0.5 to $2.8 \mathrm{mSv}$ of radiation from follow-up imaging, the NHS circa $£ 100$ per unnecessary follow-up computed tomography (CT) scan and aids metabolic analysis. Over time both factors may be substantial. Therefore, emphasizing the benefits and importance to patients to sieve their urine regardless of the techniques is paramount in the modern management of urolithiasis.

The number of hospital attendances and acute admissions to UK hospitals due to urolithiasis is increasing with over 87,000 stone related acute care admissions in the year 2017-2018. ${ }^{1}$ The British Association of Urological Surgeons (BAUS) have published guidelines for the management of patients presenting with ureteric colic ${ }^{2}$. Patients with a nonobstructing ureteric stone and no evidence of sepsis or renal compromise can be managed expectantly as an outpatient, negating the need for inpatient care. ${ }^{2}$ The recommendation is that this subgroup of patients should subsequently be followed up in the outpatient setting within 4 weeks with some form of imaging. Trying to achieve this recommendation can be timely, resource-intensive and not always feasible within the timeframe specified.

Many consensus groups also advocate stone analysis in those presenting with urolithiasis to try and combat the health and economic burden associated with patients forming multiple stones. ${ }^{2-5}$ Stone analysis is relatively inexpensive and can lead to the identification of an easily treatable condition. This will allow clinicians to provide patients with bespoke dietary and lifestyle advise to try and prevent further stone formation. ${ }^{3,4,5}$ Stone retrieval in patients being managed expectantly would be beneficial in many ways as it would not only allow stone analysis but could also potentially negate the need for further imaging, thus alleviating the pressure on our radiology departments.

Stone retrieval typically requires patients to sieve their urine for them to retrieve a stone for analysis. There are many ways in which urinary sieving can be performed, but anecdotally compliance with this practise is poor. Paramount medical solutions have devised a product - the UroPro ${ }^{\odot}$ stone catcher- to try and improve compliance with urinary sieving. This study aimed to see if introducing the UroPro ${ }^{\mathscr{C}}$ stone catcher (Figure 1) into our hospital practise would improve stone retrieval. This, in turn, could increase the numbers of stone sent away for biochemical analysis and potentially reduce the number of follow-up CTs performed.

\section{METHOD}

The study was carried out between November 2018 and July 2019. Patients undergoing Extracorporeal

FIG. 1 Showing the UroPro ${ }^{\odot}$ Stone Catcher.
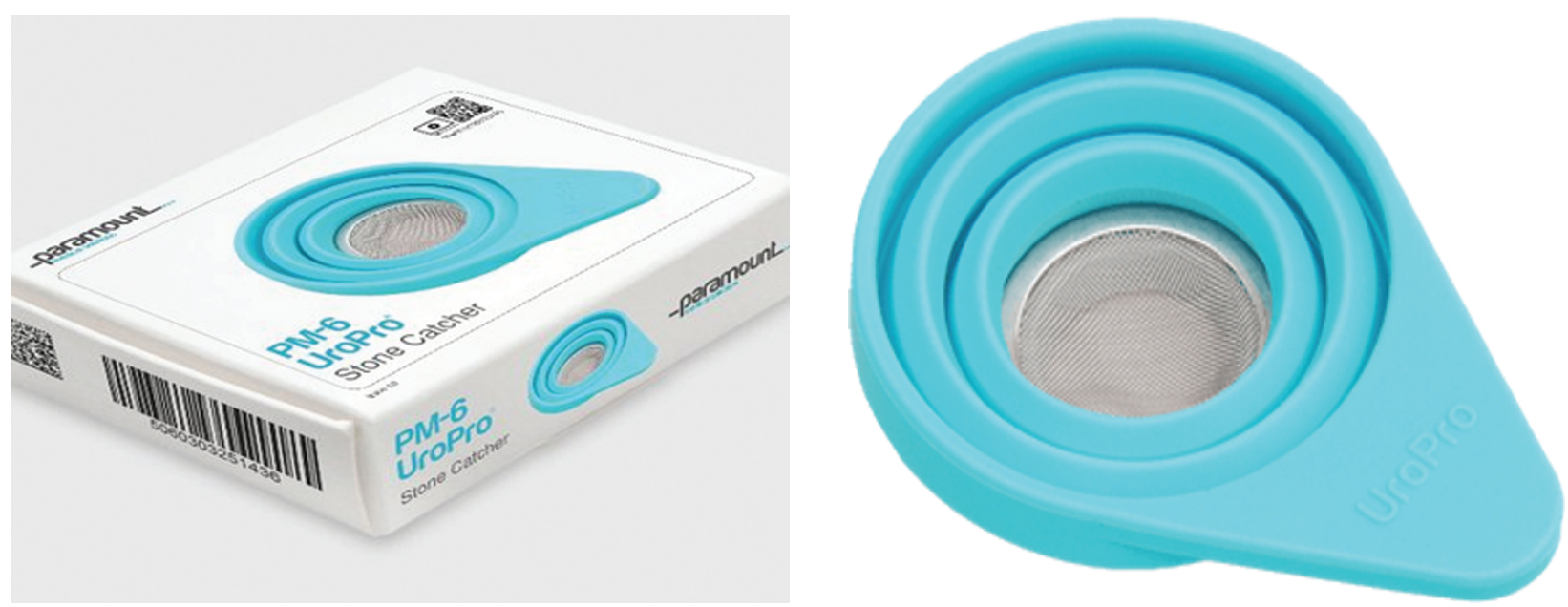

J Endolum Endourol Vol 3(1):e39-e46; March 3, 2020.

This article is distributed under the terms of the Creative Commons Attribution-

Non Commercial 4.0 International License. CKhela, et al. 
Shockwave Lithotripsy (ESWL) and those presenting acutely with ureteric calculi who were deemed suitable for conservative management considering the BAUS guidelines were discharged with a UroPro ${ }^{\odot}$ stone catcher. To determine the stone size the maximum width and length in the coronal plane was taken along with the maximal dimension in the axial plane. The patients were given advise on how to use the product and to bring any fragments to their next follow-up appointment. Patients were also given a questionnaire regarding compliance with the product, ease of use and preferred methods of urine sieving.

\section{RESULTS}

There were 27 patients recruited for the project originally: 13 from acute attendances and 14 from ESWL. Figure 2 gives an overview of the study participants. 22 patients attended follow-up and returned their questionnaires. 5 patients failed to attend their follow-up appointments and were uncontactable by telephone.

\section{Acute Patients}

The outcome of the 10 patients who were managed conservatively and discharged home with a stone catcher is outlined in Figure 3. A total of 30\% $(\mathrm{n}=3)$ caught a stone, 2 brought the stone to the clinic allowing biochemical analysis. These patients were able to avoid undergoing further imaging and were discharged from follow-up. The patient who did not bring his stone to the clinic attended acutely unwell and underwent a CT scan, the concern was of a ureteric stone causing sepsis. The cause was found to be pyelonephritis secondary to outflow obstruction and complete passage of the previous ureteric stone. $20 \%$ $(n=2)$ returned to the clinic without having caught a stone and underwent follow-up imaging. These 2 patients were found to have passed their stone but had failed to catch it with the stone catcher. Another patient failed to catch his stone but saw himself pass it into the toilet and thus avoided follow-up imaging. $30 \%(n=3)$ of patients required intervention, in the form of ureteroscopy and laser, following a trial of conservative management and thus did not pass or catch their stone. 1 patient was taken to theatre acutely and the stone was found in the bladder.

\section{Stone Characterization}

All patients managed conservatively had a stone measuring $8 \mathrm{~mm}$ or less in its maximal dimension. The average and median stone size was $4 \mathrm{~mm}$ (range $2-8 \mathrm{~mm})$. For the $70 \%(\mathrm{n}=7)$ of patients who passed their stone without intervention, all did so within 6 weeks. The average maximal stone dimension was 4.6 $\mathrm{mm}$ (range $2-8 \mathrm{~mm})$. The $30 \%(\mathrm{n}=3)$ of patients who required intervention all had a stone that was $4 \mathrm{~mm}$

FIG. 2 Showing an overview of patients in the study.

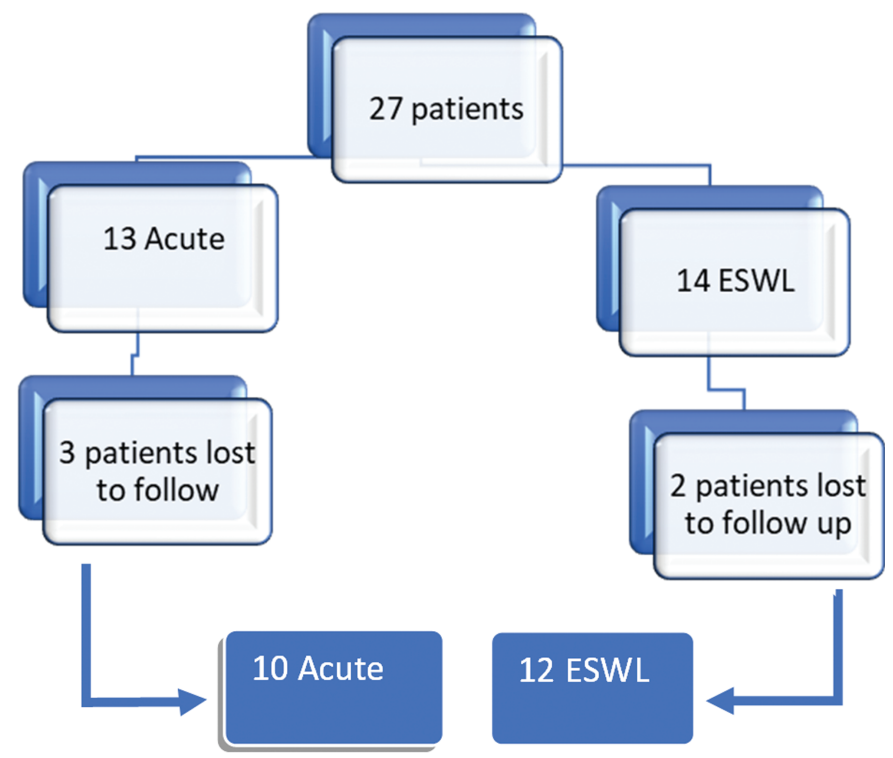

J Endolum Endourol Vol 3(1):e39-e46; March 3, 2020.

This article is distributed under the terms of the Creative Commons Attribution-

Non Commercial 4.0 International License. CKhela, et al. 
FIG. 3 Illustration of the outcome of patients from the acute arm of the study.

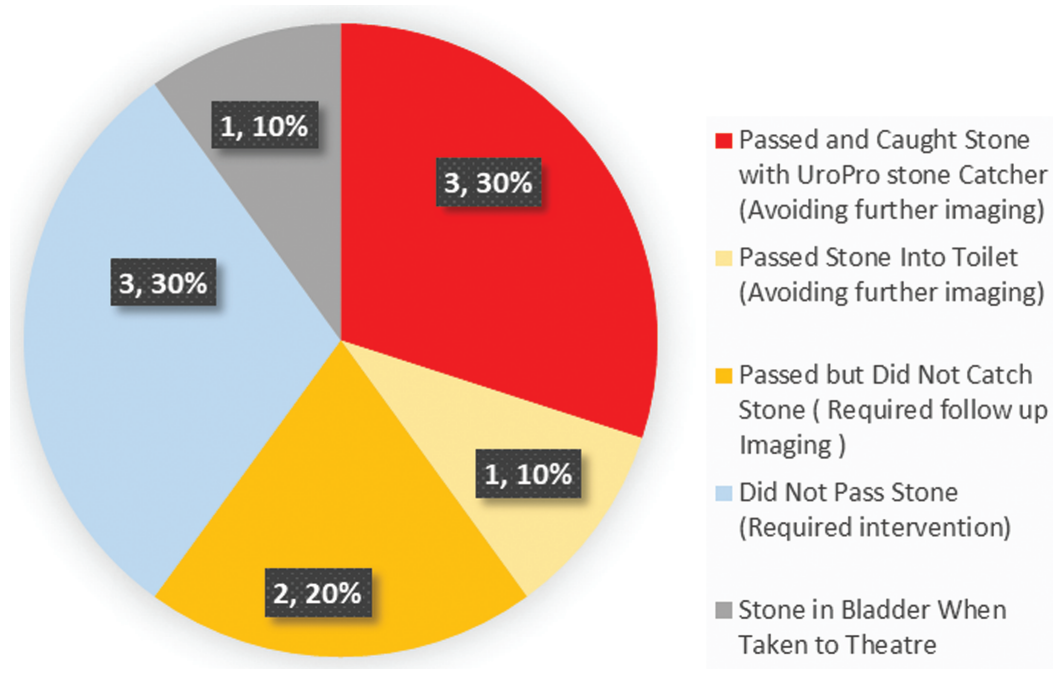

in maximal dimension, 2 were at the vesicoureteric junction (VUJ) at diagnosis, 1 was mid ureteric. 2 were stented as an emergency due to pain. 1 of the patients who had a VUJ stone at diagnosis failed to pass his stone on subsequent imaging and was admitted for semi-elective stenting before ureteroscopy (URS) and laser.

\section{ESWL Patients}

Of the 14 patients recruited from ESWL, 3 failed to attend their follow-up sessions and were discharged from the service following 2 non -attendances. 16\% $(\mathrm{n}=2)$ patients managed to catch a fragment of stone that was big enough to send away to the lab for biochemical analysis. A total of $42 \%(n=5)$ of patients passed reported passing dust and debris that clogged up the filter and could not retrieve any fragments for analysis. As well, 2 of the $12(14 \%)$ went on to have ureteroscopy and laser fragmentation of their stone.

Overall, the stone analysis was performed in $20 \%$ of patients in this study, compared to $8 \%$ of patients in a previous audit done at the same trust. The need for follow-up imaging was reduced by $13 \%$ due to the active retrieval of stones using the stone catcher.

\section{Compliance and Ease of Use}

All 22 patients who attended follow-up completed the patient survey regarding the ease of use of the stone catcher. $59 \%(n=13)$ of patients described the stone catcher as quite or very easy to use (Figure 4). And, $14 \%(n=3)$ were indifferent towards the product describing it as neither easy nor hard. The remaining $27 \%(n=6)$ described the product as quite or very hard to use. Figure 5 illustrates patients reported compliance with the product. $73 \%(n=16)$ reported using the stone catcher between 75 and $100 \%$ of the time between appointments. There was 1 person who did not like or use the stone catcher at all and $23 \%(n=5)$ stated they used the stone catcher around $25 \%$ of the time.

Despite the reported ease of use and compliance only $27 \%(n=6)$ would choose to use a stone catcher again when given a choice of sieving methods. As Figure 6 shows $73 \%(n=16)$ would opt to use one of the older more traditional methods of sieving compared to the stone catcher. $32 \%(n=7)$ would prefer to urinate into a clear bottle and sieve the contents later whilst $27 \%$ $(n=6)$ would preferentially urinate directly through a tea strainer. $5 \%(\mathrm{n}=1)$ would urinate through a stocking, whilst $10 \%(\mathrm{n}=2)$ had no preference.

Patients were given a free text space for comments about the stone catcher and to explain their rationale for their preferred sieving method. Most patients commented that the more traditional methods were "cheaper," "easier," and "more hygienic." The over-riding feedback from females regarding the stone catcher was that the handle was "too short" hence making the product unhygienic. Younger men found their flow 
FIG. 4 Graph demonstrating how easy to use patients perceived the stone catcher to be.

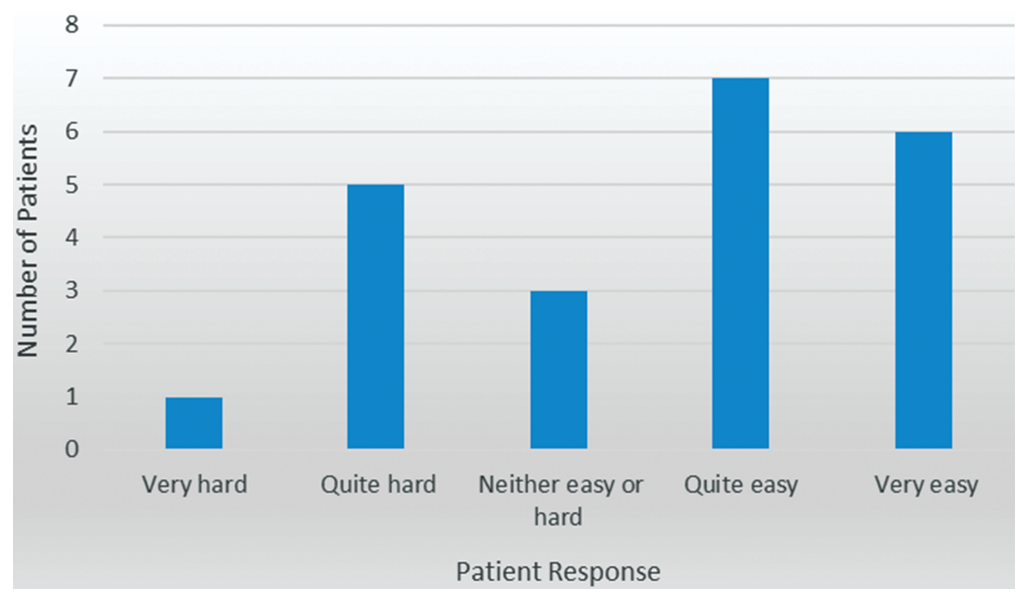

FIG. 5 Graph demonstrating patients’ self-reported compliance with the UroPro ${ }^{\odot}$ Stonecatcher.

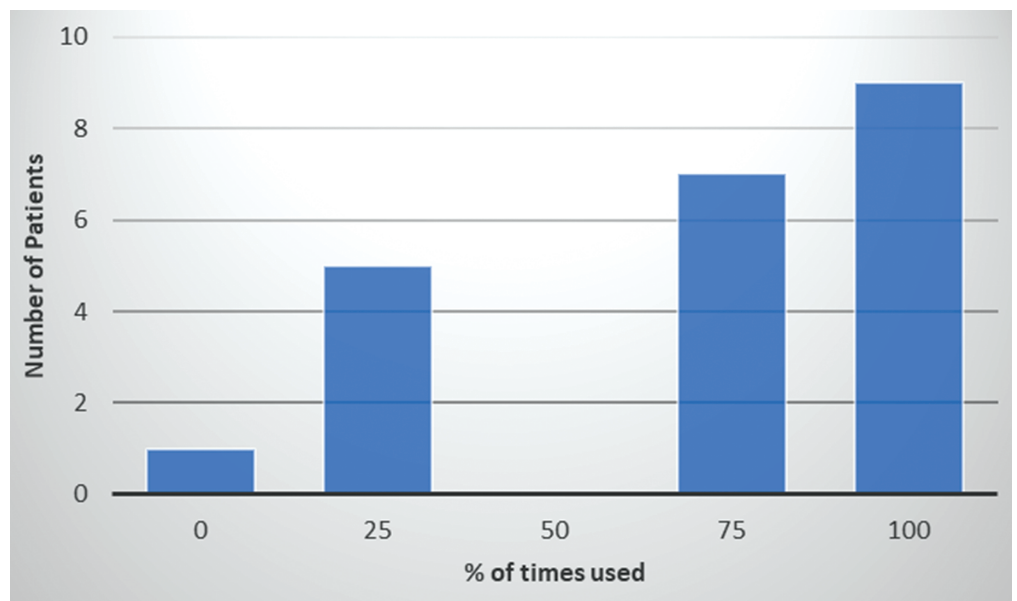

FIG. 6 Graph highlighting patient's preferred methods of sieving urine.

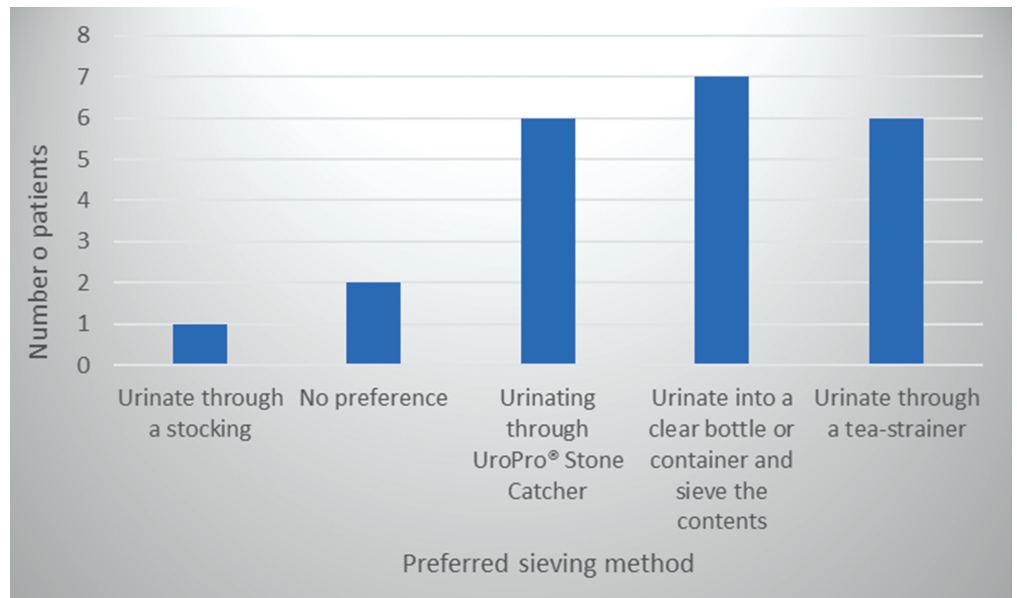

J Endolum Endourol Vol 3(1):e39-e46; March 3, 2020.

This article is distributed under the terms of the Creative Commons AttributionNon Commercial 4.0 International License. CKhela, et al. 
of urine was too much for the stone catcher, causing the device to overflow, again making it "unhygienic." Half of the patients who opted for the older methods wanted the Stone catcher to be "bigger."

\section{DISCUSSION}

There are several guidelines available to clinicians on the management of stone disease and particularly how to identify those groups of patients who require immediate intervention and those that can be managed expectantly. ${ }^{2-5}$ The biggest stone in our study was $8 \mathrm{~mm}$ in maximal dimension and $70 \%$ of our patient cohort successfully passed their stone without surgical intervention within 6 weeks. This is in keeping with previously reported passage rates for similar size stones. ${ }^{6-8}$ Our rate of intervention for recurrent colic was higher than other papers at $20 \%{ }^{7}$ Interestingly all patients that required stenting either due to ongoing severe symptoms or failure of passage were male and had left-sided stones measuring $4 \mathrm{~mm}$ or less in maximal dimension. BAUS suggest clinic review with imaging at 4 weeks to offer definitive treatment if the stone Is still present. However, studies have shown that larger stones can take a longer period to pass compared to stones less than $4 \mathrm{~mm}$ and the classical study by Miller and Kane showed that even stones as large as $6 \mathrm{~mm}$ have a $95 \%$ chance of passage at 40 days. In this study, $100 \%$ of the stones measuring $4 \mathrm{~mm}$ or above passed spontaneously within a couple of days or week. The only stone that persisted at 2 months measured less than $4 \mathrm{~mm}$, but should stones be given longer if they haven't passed at 4 weeks instead of offering definitive treatment at this point?

The need to follow-up all conservatively managed stones within 4 weeks with imaging can put significant strains on an already stretched system. ${ }^{9-11 .}$ Having said this it is incredibly important that all stone patients are appropriately followed up to avoid the severe complications of retained ureteric stones which can subsequently cause a whole host of problems for both patient and clinician. ${ }^{12}$

In this study, $40 \%$ of our acute patients were able to prevent further imaging by either retrieving their stone and bringing it to the follow-up appointment or taking a picture of the passed stone in the toilet. One could argue that this could have significant implications for stone follow-up. A 40\% reduction in the number of follow-up CTs or X-rays performed from multiple stone clinics could have a significant impact on our already overworked radiology departments. More importantly, negating the need for a follow-up CT scan would reduce the amount of ionizing radiation a patient would be exposed to. Due to our growing knowledge of the risks associated with ionizing radiation the International Commission on Radiological Protection has defined the threshold of safe radiation exposure for a patient as $50 \mathrm{mSv}$ a year and this has remained unchanged for several years. ${ }^{13}$ There is a growing body of evidence suggesting that the potential risk of malignancy increases with each CT scan. ${ }^{14,15}$ Furthermore the younger the patient the bigger the lifetime risk of developing a solid organ or hematological malignancy with each $\mathrm{mSv}$ of radiation an individual is exposed to. ${ }^{16}$ The average dose for a CT KUB depends on the machine and the number of slices obtained for the imaging. For a routine CTKUB the dose is between $4.3-8.5 \mathrm{mSv}$. If a low dose CTKUB is ordered this exposure can be reduced to $0.98-1.5$ $\mathrm{mSv}{ }^{17}$ Arguably these doses are small, however, we must remember how much the use of ionizing radiation has increased both diagnostically and therapeutically over the years. ${ }^{15}$ The doses patients are exposed to for other diagnostic and therapeutic imaging such as an arteriovenous CT scan of the abdomen and pelvis or a coronary angiogram are between $24-32 \mathrm{msV}$ of radiation each. Considering these other tests, it is easy to see how quickly a patient can exceed the safe radiation threshold and thus increasing their lifetime risk of malignancy. ${ }^{16,18}$ As such, we should always endeavour to avoid exposing patients to unnecessary irradiation wherever possible. Currently, no published Urolithiasis guidelines recommend sieving urine as part of conservative management, however, If stone retrieval allows us to avoid requesting follow-up imaging for patients then we should certainly consider incorporating this into our practise. Furthermore, stone retrieval in these patients would have the added benefit of allowing stone analysis as part of their recommended metabolic workup to screen for easily reversible causes. ${ }^{3-5}$

The success of stone catcher in ESWL patients was less so compared to that for our conservatively managed acute cohort. The main reason for this was 
due to the production of lots of dust that clogged up the stone catcher sieve as opposed to producing large stone fragments that patients could retrieve. All the patients who described the stone catchers as "quite hard" or "very hard" to use were patients undergoing ESWL, conversely those patients being conservatively managed generally found the stone catcher easy to use. The over-riding feedback from ESWL patients was that the stone catcher became "clogged" "overflowed" and therefore was unhygienic. All of these patients, bar 1, preferred more traditional methods of urinating through a tea strainer or into a bottle and then sieving the contents later. In comparison, patients who were managed conservatively found the stone catcher "easy to us," "simple," and "ingenious" but even in this cohort, the younger male patients and females found the stone catcher overflowed due to its inability to cope with large volumes of urine. Despite the reported ease of use in conservatively managed patients, they still preferred to use older methods of sieving. The main reasons cited for these preferences were that they were "easier to use" and "cheaper." At a time when the NHS is struggling for funds, it is refreshing that patients would prefer something tried, tested and readily available to them as opposed to wishing for something novel at the expense of the NHS. ${ }^{9}$

\section{CONCLUSION}

To conclude, we would encourage the use of urinary sieving in all patients who are being treated conservatively for ureteric stones. Stone retrieval in any form remains advantageous as it can save patients between $0.5-2.8 \mathrm{~m} \mathrm{~Sv}$ of radiation in follow-up imaging and can also save the NHS per unnecessary follow-up CT scan. Stone analysis also enables clinicians to provide bespoke dietary and lifestyle advice to patients to reduce the risk of further stone formation. This would again save the NHS money and be advantageous for patients. The UroPro ${ }^{\odot}$ stone-catcher did increase the number of stones caught and sent for analysis. Whilst novel and seemingly simple to use the stone catcher retails at $£ 5.50$ making it much more expensive than some of the more traditional sieving methods - which patients seemed to prefer in this study. Patients must be made aware of the different methods available to them so they can use the method most suitable and acceptable to them. The stone catcher does have its advantages and some patients did prefer this device; thus, it would be up to individual trusts if they wished to invest in them. Overall, emphasizing the benefits and importance to patients to sieve their urine regardless of the techniques is paramount in the modern management of urolithiasis

\section{DISCLOSURE}

No Grant Support was received for this article.

\section{REFERENCES}

1. Hospital Episode Statistics (HES) Data 2017-18. Available at: https://digital.nhs.uk/data-and-information/ publications/statistical/hospital-admitted-patient-care -activity/2017-18.

2. Tsiotras A, Smith D, Pearce I, O'Flynn K, Wiseman O. British Association of Urological Surgeons standards for management of acute ureteric colic. J Clin Urol 2018;11(1):58-61.

3. NICE. NICE Guideline 118. Renal and ureteric stones: assessment and management. 2019. Available at: https:// www.baus.org.uk/_userfiles/pages/files/professionals/ sections/endourology/Renal $\% 20$ and $\% 20$ Ureteric $\% 20$ Colic\%20Jan\%202019.pdf.

4. Turk C, Neisius A, Petrik A, Seitz C, Skolarikos A, Thomas K, Donaldson JF, Drake T, Grivas N, Ruhayel Y. EAU Guidelines on Urolithiasis 2018. Available at: https://uroweb.org/wp-content/uploads/EAU-Guidelineson-Urolithiasis-2018-large-text.pdf.

5. Pearle MS, Goldfarb DS, Assimo DG, Curhan G, Denu-Ciocca CJ, Matlaga BR, Monga M, Penniston KL, Preminger GM, Turk TMT, White JR. Medical management of kidney stones. AUA Guideline; 2019. Available at: https://www.auanet.org/guidelines/ kidney-stones-medical-mangement-guideline

6. Miller OF, Kane CJ. Time to stone passage for observed ureteral calculi: A guide for patient education. J Urol 1999;162:(3)688-91.

7. Yallapa S, Amer T, Jones P, Greco F, Tailly T, Somani BK, Umez-Eronini N, Aboumarzou OM. Natural history of conservatively managed ureteral stones: analysis of 6600 patients. J Endourol 2018;32:( 5)371-79.

8. Jendeberg J, Geijer H, Alshamari M, Cierzniak B, Lidén M. Size matters: The width and location of a ureteral stone accurately predict the chance of spontaneous passage. Eur Radiol 2017;27(11):4775-785. 
9. Robertson R, Wenzel L, Thompson J, Charles A. Understanding NHS financial pressures; 2017; Available at: https://www.kingsfund.org.uk/sites/default/files/field/ field_publication_file/Understanding $\% 20 \mathrm{NHS} \% 20$ financial $\% 20$ pressures $\% 20-\% 20$ full $\% 20$ report.pdf.

10. The British Medical Association. Working in a system that is under pressure; 2018. Available at: https:// www.bma.org.uk/collective-voice/influence/keynegotiations/nhs-pressures/working-in-a-system-under -pressure.

11. Niblett DJ. Pressures in outpatient clinics: Putting up with overcrowded clinics disguises need for change. Br Med Assoc 1998;317:541.

12. Roberts WW, Cadeddu JA, Macali S, Kavoussi LR, Moore RG. Ureteral stricture formation after removal of impacted calculi. J Urol 1008;159(3):723-26.

13. ICRP Publication 60: Recommendations of the International Commission on Radiological Protection, 60. Annals of the ICRP 1991;21:1-3
14. Sodickson A, Baeyens PF, Andriole KP, et al. Recurrent $\mathrm{CT}$, cumulative radiation exposure, and associated radiation-induced cancer risks from $\mathrm{CT}$ of adults. Radiology 2009;251:175-84.

15. Brenner DJ, Hall EJ. Computed tomography: an increasing source of radiation exposure. N Engl J Med 2007;357:2277-84.

16. Preston DL, Shimizu Y, Pierce DA, Suyama A, and Mabuchi K. Studies of mortality of atomic bomb survivors. report 13: solid cancer and noncancer disease mortality. 1950-1997. Radiat Res 2003:160(4):381-407.

17. Hyams ES, Shah O. Evaluation and follow-up of patients with urinary lithiasis: minimizing radiation exposure. Curr Urol Rep 2010;11(2):80-86.

18. Smith-Bindman R, Lipson J, Marcus R, Kim KP, Mahesh M, Gould R, Gonzalez AB, Miglioretti D. Radiation dose associated with common computed tomography examinations and the associated lifetime attributable risk of cancer. Arch Intern Med 2009;169(22):2078-86. 